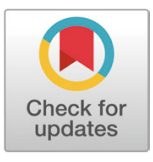

Received: Nov 6, 2019

Revised: Feb 3, 2020

Accepted: Feb 4, 2020

*Corresponding author

Jung Hwan Jeon

National Institute of Animal Science,

Rural Development Administration,

Wanju 55365, Korea.

Tel: +82-63-238-7407

E-mail: jeon75@korea.kr

Copyright $@ 2020$ Korean Society of

Animal Sciences and Technology.

This is an Open Access article

distributed under the terms of the

Creative Commons Attribution

Non-Commercial License (http://

creativecommons.org/licenses/by-

nc/4.0/) which permits unrestricted

non-commercial use, distribution, and

reproduction in any medium, provided

the original work is properly cited.

ORCID

$\mathrm{Si}$ Nae Cheon

https://orcid.org/0000-0003-1865-8970

Yang-Ho Choi

https://orcid.org/0000-0003-2107-3236

Kyu-Hyun Park

https://orcid.org/0000-0002-6390-5478

Jun Yeob Lee

https://orcid.org/0000-0001-8074-586X

Jung Hwan Jeon

https://orcid.org/0000-0001-9725-547X

Competing interests

No potential conflict of interest relevant

to this article was reported.

Funding sources

This work was carried out with the

support of "Cooperative Research

\section{Adaptational changes of behaviors in hens introduced to a multi-tier system}

\author{
Si Nae Cheon ${ }^{1}$, Yang-Ho Choi ${ }^{1,2}$, Kyu-Hyun Park ${ }^{3}$, Jun Yeob Lee ${ }^{4}$ and \\ Jung Hwan Jeon ${ }^{4 *}$ \\ ${ }^{1}$ Department of Animal Science, and Institute of Agriculture and Life Sciences, Gyeongsang National \\ University, Jinju 52828, Korea \\ ${ }^{2}$ Institute of Agriculture and Life Sciences, Gyeongsang National University, Jinju 52828, Korea \\ ${ }^{3}$ College of Animal Sciences, Kangwon National University, Chuncheon 24341, Korea \\ ${ }^{4}$ National Institute of Animal Science, Rural Development Administration, Wanju 55365, Korea
}

\section{Abstract}

This study was conducted to investigate behavioral changes in laying hens (Hy-Line Brown) after transfer to a multi-tier system from the floor system and to examine their production performance. The hens were randomly divided into two groups and were allocated to the multi-tier system and the floor system at a commercial farm. Behavior of the laying hens was recorded by CCD (charge-coupled device) cameras and a digital video recorder. The data were scanned every 2 min to obtain an instantaneous behavioral sample or were immediately counted whenever the hens exhibited a designated behavior. Behavior changed dramatically during the first seven days. Egg production was higher in the multi-tier system, while cracked and dirty eggs were more frequent in the floor system $(p<0.05)$. No differences in mortality rate or egg quality were observed between the groups. In conclusion, the hens needed at least seven days to adapt to the multi-tier system. The multi-tier system was more efficient than the floor system in terms of production performance.

Keywords: Animal welfare, Behavior, Floor system, Laying hens, Multi-tier system, Production performance

\section{INTRODUCTION}

The recent increasing public interest in animal welfare has aroused sentiments so that many countries have tightened the laws and guidelines of animal welfare and animal protection in stages. Although animal welfare certification standards differ among countries due to cultural and religious differences, cages have generally been banned for laying hens. The installation of nest boxes, perches, and sand boxes is basic and essential in a rearing system. The laying hen welfare certification standard in Korea includes banning cage rearing and requires less than nine head per $\mathrm{m}^{2}$, a $4 \mathrm{~cm}$ round type feeder space per head, $1 \mathrm{~m}^{2}$ or more of nest boxes per 120 head, and $15 \mathrm{~cm}$ or more of perch space per head. Floor type or free range type systems have been used as alternatives to an animal welfare system; however, these systems require more area to rear laying hens and more labor time to collect eggs. A multi-tier system is considered an alternative to floor type or free range systems, and has advantages of using a feeder, nest boxes, 
Program for Agriculture Science and Technology Development (Project No. PJ90718903)," Rural Development Administration, Korea.

Acknowledgements

This study was supported by 2013 collaborative research program between university and Rural Development Administration, Korea

Availability of data and material Upon reasonable request, the datasets of this study can be available from the corresponding author.

\section{Authors' contributions}

Conceptualization: Jeon JH.

Data curation: Cheon SN, Jeon JH.

Formal analysis: Cheon SN, Jeon JH.

Methodology: Cheon SN, Jeon JH

Software: Cheon SN, Jeon JH.

Validation: Cheon SN, Jeon JH.

Investigation: Cheon SN, Jeon JH.

Writing - original draft: Cheon SN.

Writing - review \& editing: Cheon SN, Choi

YH, Park KH, Lee JY, Jeon JH.

Ethics approval and consent to participate The experimental protocol for this research was reviewed and approved by the Institutional Animal Care and Use Committee from National Institute of Animal Science. and a perch vertically and horizontally which help express hens' natural behaviors and facilitate collect egg collection and manure removal.

Environment enrichment is an increasing method of research for improving welfare of domestic animal by maintaining of their natural behavior and productivity. It helps to reduce extreme stress, decrease abnormal or damage behavior, improve physical health and enhance immunity [1]. However, it can have some adverse effects on animal health due to lack of skill to navigate in complex environment [2] or overcrowding as insufficient space for feeding, drinking and dustbathing [3]. Also, early life stress has been shown to exert profound short- or long-term effects from rearing environment to adult environment [4]. For example, severe feather pecking of young hens during rearing period develop high levels of feather damage later in life [5]. It is possible to predict development of welfare problem during rearing period and reduce by providing appropriate environment [6]. It needs to evaluate the performance of the multi-tier system under production conditions with regard to behavior and productivity.

This study was conducted to investigate laying hens' initial behavioral changes in a multi-tier system and to compare egg productivity and egg quality of the multi-tier system with those of the floor system.

\section{MATERIALS AND METHODS}

\section{Animals and management}

A total of 1,974 Hy-Line Brown hens were randomly divided into two groups and allocated to either the floor system or the multi-tier system at 11 weeks of age under commercial farm conditions (Fig. 1). Both housing systems were provided with perches, nest boxes, and litter on the same floor area $(7 \times 20 \mathrm{~m})$, and the floor area was covered with $5 \mathrm{~cm}$ deep of wood shavings. The multi-tier system was equipped to automatic facilities, such as egg collection systems and manure removal belts. Commercial standard layer diets were provided at approximately 05:30 and $16: 30 \mathrm{~h}$ and water was available ad libitum. The photoperiod was 14-h light: 10-h dark with the lights on at 5:30 am.

\section{Housing system}

The floor system had feeders and drinkers placed in the middle and perches and nest boxes on its each side. The multi-tier system was equipped with three tiers with automatic chain feeders on the first tier, nipple drinkers and integrated nests on the second, and perches on the top tier. A schematic drawing of the housing system is provided in Fig. 2. Conveyor belts installed under the lower and
A

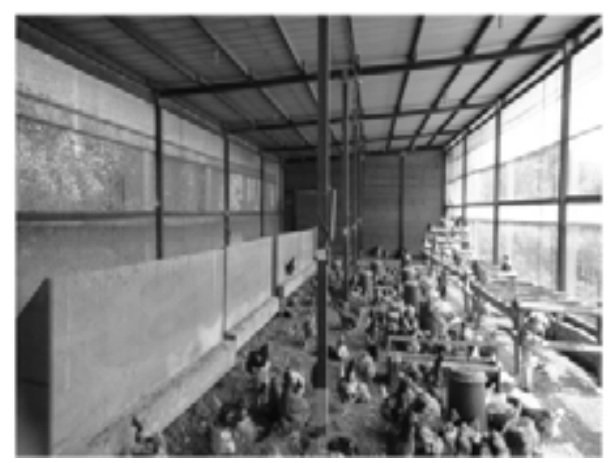

B

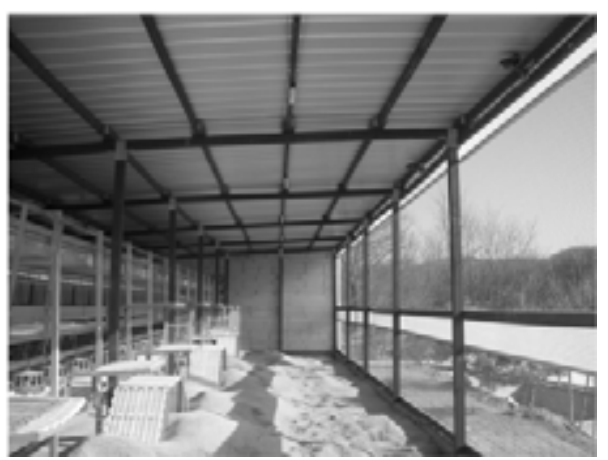

Fig. 1. Photograph of the two housing systems used in this study. (A) Floor system, (B) Multi-tier system. 


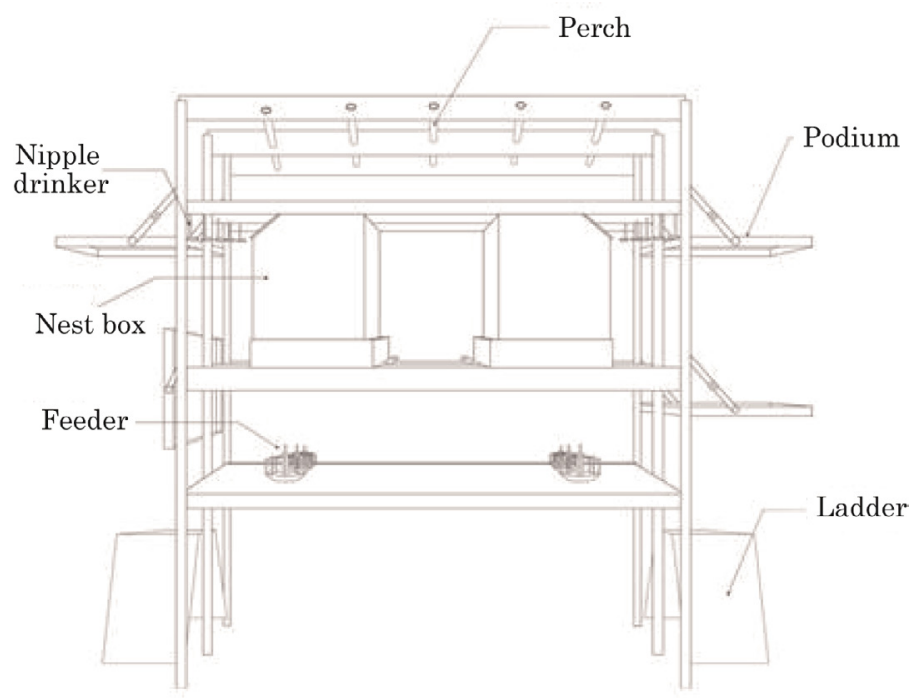

Fig. 2. Schematic drawing of the multi-tier system.

top tier floors automatically removed droppings. Its height was within $2 \mathrm{~m}$ from the ground to the top and there was $30 \mathrm{~cm}$ in between tiers. Ladders or podiums were provided to go up or down the tiers. Perches allowed a $15 \mathrm{~cm}$ space for each bird, and nest boxes offered $1 \mathrm{~m}^{2}$ nest space per 100 hens. The doors of the nest boxes were automatically closed during the night and their ends were rounded to prevent injury (Fig. 3). The floor of the nest was made of a perforated rubber plate to prevent the hens from sliding down the slope (about $8^{\circ}$ ). Nipple drinkers were installed in front of the nests and one nipple was provided per 10 hens.

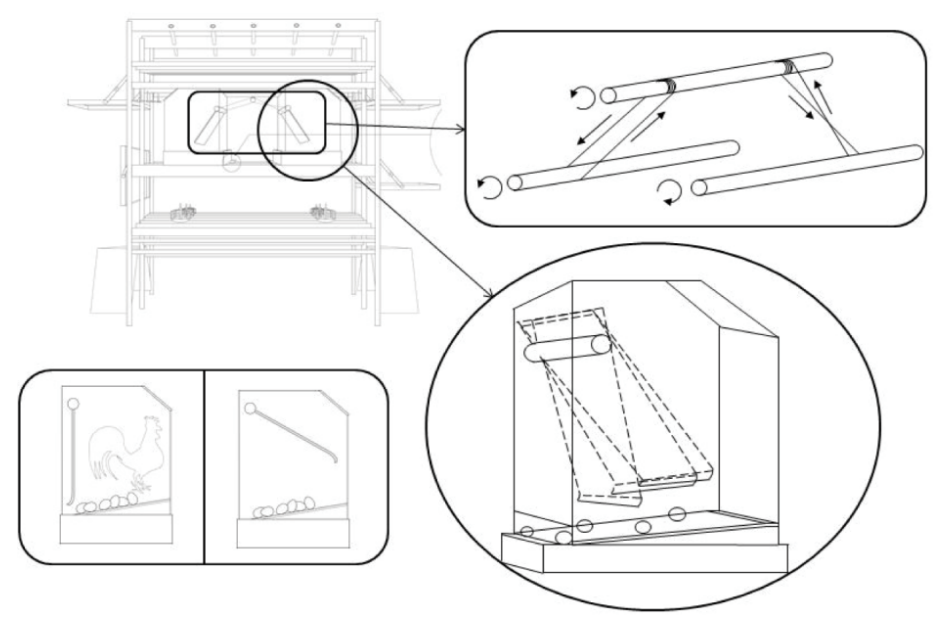

Fig. 3. A device designed to prevent hens from entering the nest box during the night. 


\section{Behavioral observations}

Behavioral observations were generally conducted by the focal sampling method after tied the races up of legs or dying the wings of a small group of laying hens. However, viewing of marked birds was often obstructed when they moved around the multi-tiers, and it was impossible to distinguish hens during the dark phase. In some studies, behavioral observations were extracted in the form of the total number of birds counted within marked sections [7]. Therefore, data were recorded for seven behaviors using CCD (charge-coupled device) cameras and a digital video recorder within a marked section. Hens' behaviors are defined in Table 1. We monitored for $24 \mathrm{~h}$ per day for 10 days. General behavior (feeding, drinking, perching, and dust-bathing) was determined from instantaneous scan sampling and was continuously observed at 2-min intervals throughout the experimental period. Specific behaviors, such as nest visiting, feather pecking, and wing-flapping, were instantly counted at the time the behavior was exhibited.

Not all layers were in the egg laying period, so the number of visited nests was counted. Distinction between general feather pecking and severe feather pecking was not considered. All behavioral analyses were carried out by the same person.

\section{Egg production and quality}

Between 19 and 44 weeks of hens' age, feed consumption and mortality were recorded. Eggs were collected daily, from which egg yield and the number of cracked and/or dirty eggs was recorded. Egg weight was measured after washing and drying them. Eggshell break strength was measured using an FHK eggshell strength tester (Fujihara, Tokyo, Japan). Eggshell thickness was measured by using a micrometer, and so were yolk color, albumen height and Haugh unit (HU) done with a QCM + System (TSS, York, England).

\section{Statistical analysis}

After being tested for normality and circularity to meet the assumptions, square root transformation of the data was performed if necessary to meet those requirements. All data were statistically analyzed using the PROC GLM procedure of SAS (SAS Inst., Cary, NC, USA) for randomized design. Post hoc testing was performed using Fisher's least-significant-difference (LSD). All differences were considered significant at $p<0.05$. The results in tables are presented as means and standard deviations.

\section{RESULTS AND DISCUSSION}

\section{Feeding}

The hourly feeding pattern consistently showed two peaks during the experiment (Fig. 4a; $p<0.05$ );

Table 1. The mutually exclusive behavioral categories used for the behavioral observations

\begin{tabular}{ll}
\hline \multicolumn{1}{c}{ Behavior } & \\
\hline Feeding & Lowering head into feed trough \\
Drinking & Pecking at nipple drinker \\
Perching & Upright position on the perch \\
Dust bathing & Rubbed head or side and vertical wing shaking in sand \\
Nest visiting & Entered the nest box \\
Wing flapping & Spreads both wings and moves them up and downwards \\
Pecking & $\begin{array}{l}\text { Pecking the feathers, neck, head, and tail of other hens or two hens face to face } \\
\text { trying to peck each other. }\end{array}$ \\
\hline
\end{tabular}


one in the morning (05:00-06:00) and the other in the afternoon (16:00-17:00), corresponding to the results of Choi et al. [8] and Jordan et al. [9]. The hens consumed about $60 \%$ of daily feed intake from 05:00 to 12:00 and ate the remaining 40\% from 13:00 to 20:00, contrary to Hetland et al. [10]. Savory [11] reported a similar result that non-layers usually eat more in the morning than layers. Some evidence indicates that time of oviposition is negatively correlated with feed consumption. Feed intake decreases an hour or two prior to oviposition, but increases immediately afterwards $[8,12,13]$. In this study, feeding behavior was probably influenced more by other factors, and not time of oviposition, as the hens were immature. Laying hens were likely to attempt to feed when feeders were filled with a commercial diet.

The daily feeding pattern was slightly reduced on day 6 (Fig. $5 a ; p<0.05$ ) which may have been a temporary fluctuation due to the sudden appearance of humans rather than the rearing environment. Feeding frequency increased the next day and did not differ during the remainder of the experimental period. It seemed that feeding behavior was not greatly impacted by the new environment. Several studies have found that feeding frequency is strongly influenced by social rank [14]. Dominant hens eat the most and are more aggressive at the feeder [15]. Low feed intake of subordinates causes a major drop in body weight as well as egg yield. Therefore, adequate feeder space should be provided so all hens can feed synchronously [16,17].

\section{Drinking}

The hourly drinking pattern was similar to that of feeding. Drinking time peaked one hour (06:0007:00) after peak feeding time (05:00-06:00) in the morning, except on day 3 (Fig. 4b; $p<0.05$ ). The frequency of drinking suddenly decreased on day 7 (Fig. $5 \mathrm{~b} ; p<0.05$ ) because laying hens spent more time feeding, but their feeding increased slightly more than usual the next day. It was a reward-related behavioral pattern from the previous day.

Laying hens were willing to travel up to the middle tier to drink water after feeding, suggesting that drinking was mainly influenced by feeding behavior during the rearing period. The different tiers of feeders and nipple drinkers will cause the hens to move much more than when they are provided on the same tier. Therefore, adequate nipple drinkers should be provided to laying hens.

\section{Perching}

Birds sit in elevated perches by instinct to avoid predators during the night in the wild. Domestic hens also perch [18-20], and they prefer to rest on the highest perch [21,22]. Some evidence indicates reduced fearfulness and vigilance when birds are sitting on a perch [23,24]. As expected, our results showed that all hens were willing to perch at night. The hourly perching pattern decreased significantly beginning at 05:00, but increased after 19:00 (Fig. 4c; $p<0.05$ ), which was consistent during this observation period. Other studies have reported that the presence of a perch reduces aggressive behavior between hens by allowing subordinates to avoid dominant hens and limits stocking density on the ground [25].

The daily perching pattern increased significantly over time on day 7 (Fig. 5 c; $p<0.05$ ), indicating that the hens were able to have access to and use the perches with or without using the platforms and ladders provided. Early access to a perch can affect cognitive skills of adult hens in three-dimensional space [26,27]. Installing perches improves bone strength in birds compared to those housed in cages, reduce aggressive behavior by allowing subordinates to avoid dominant hens and ease stocking density $[28,29]$. However, there can be adverse effects on physical health due to falls, collisions, and deformities caused by perch design factors such as height, width, and materials. In addition, the farmer should pay particular attention to laying hens suffering pain from injuries. 


\section{Nest visiting}

Laying hens started to visit the nest boxes early in the morning such as 05:00 $\mathrm{h}$ with the highest frequencies on days 5,7, and 9 whereas the peak frequency occurred in the afternoon on day 3 (Fig. 4d). Searching for a suitable nest site is an instinctual behavior of layer chickens. Therefore, providing nest boxes is important to improve animal welfare [30,31]. Nest site preference varies among individuals. Domestic hens generally favor elevated nests [32] and corner nests [33] which are also affected not only by surface materials, nest color and seclusion of the nest sites [34-38]. Dominant hens, which remained closer to the nest boxes, often gave aggressive pecks and laid eggs earlier in the most attractive nests [39], whereas subordinate hens were busy seeking an appropriate nest and watched for an opportunity to take an attractive nest, which made them more active prior to oviposition [40].

Nipple drinkers were placed in the front of the integrated nests, which may have stimulated the hens to enter the nest boxes at the beginning of the laying period. However, Lentfer et al. [41] demonstrated that placing nipple drinkers in front of the nest has no effect on the number of eggs laid in nests. A high number of hens on the nest platform can result in overcrowding causing agonistic behavior and laying of eggs outside nests [42]. Further research is needed to reduce the risk of overcrowding on nest platforms when hens are using nipple drinkers, as it could help to determine how to disperse the birds to the middle nests at peak laying time.

\section{Dust bathing}

Laying hens prefer to spend time dust bathing around mid-day and usually perform one bout (20$30 \mathrm{~min}$ ) every other day $[43,44]$. In the present study, most of dust bathing was observed between 09:00 to 14:00 h (Fig. 4e). However, the daily pattern was irregular and a significant increase was observed on day 4 of the experiment (Fig. 5 e; $p<0.05$ ). It was difficult to explain what stimulated hens to suddenly dust bath. Dust bathing is stimulated by multiple factors as light, heat stimuli $[45,46]$, and visual stimulus of the substrate [47]. Among various substrates, peat moss and sand are more attractive than wood shavings and straws [43,48]. An early experience with a particular substrate during the rearing period can affect the hen's choice for a particular dust-bathing substrate at a later age. Also, birds with no access to dust substrates (peat moss) during the rearing period are motivated to dust bath by other hens that had already experienced dust bathing [49]. According to Orság et al. [50], a hen's motivation to dust bath in non-cage housing systems is enhanced more than in cage type systems.

\section{Pecking}

Laying hens pull feathers out of other hens, which causes feather or skin damage, hemorrhaging, and some cannibalism can occur [51,52]. Feather pecking is a prevalent welfare problem, especially in non-cage systems [53]. In this study, feather pecking occurred intensively around feeding time in the morning (from 06:00 to 08:00) during the first seven days. The peak time was from 10:00 to $12: 00$ on day 9 , while daily feather pecking declined significantly until day 5 and at a low level thereafter (Fig. 4f, Fig. 5f; $p<0.05$ ).

Laying hens showed more activity in the morning, which was contrary to the findings of Channing et al. [7] and Ramadan and Von Borell [54]. Pecking was mostly observed on the floor. According to Nicol et al. [55], the location of the birds within the house has significant effects on feather pecking. Birds located on the floor are subjected to feather pecking [56], which is related to dust bathing or foraging and causes a crowded floor. Floor space must also be considered a factor related to feather pecking [55,57]. Laying hens showed low levels of pecking during the observation period, despite the fearfulness of unfamiliar conspecifics and the new environment. Wood-Gush [58] 
Behavior changes of hens in a multi-tier system

A

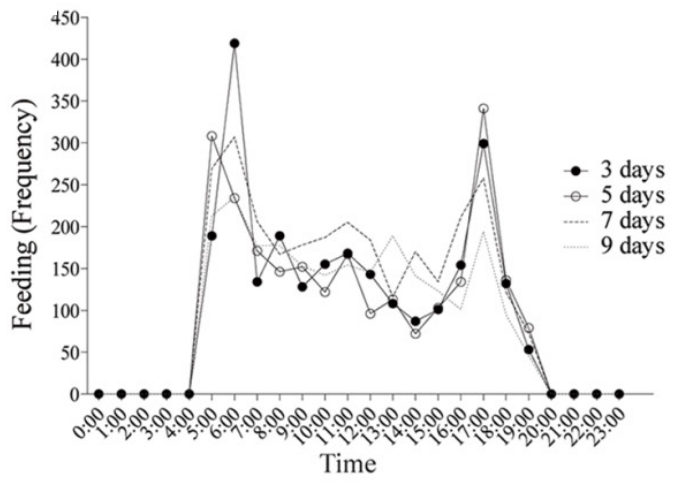

C

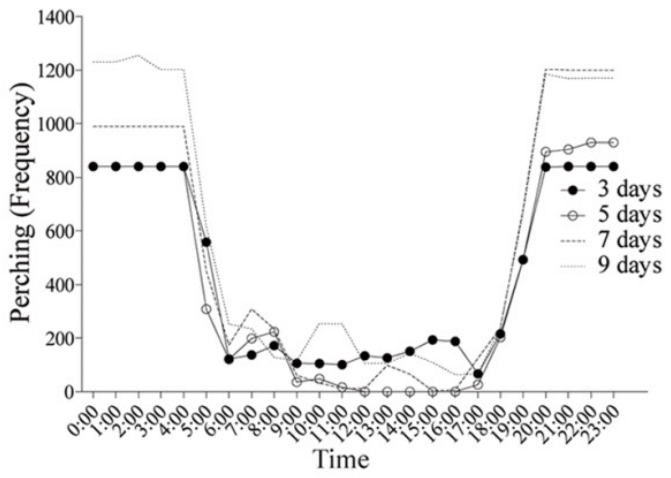

E

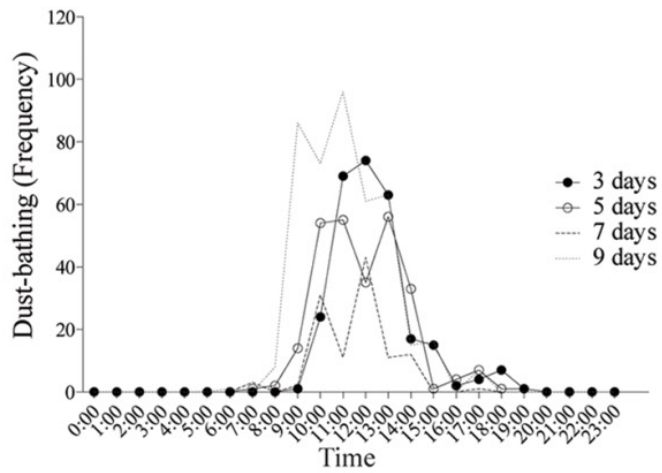

G

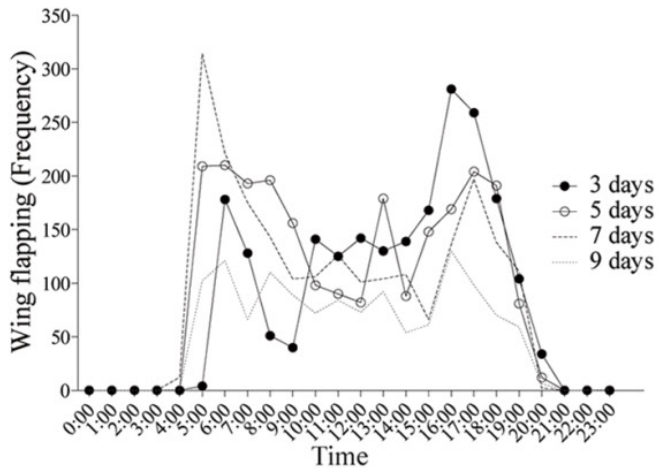

B

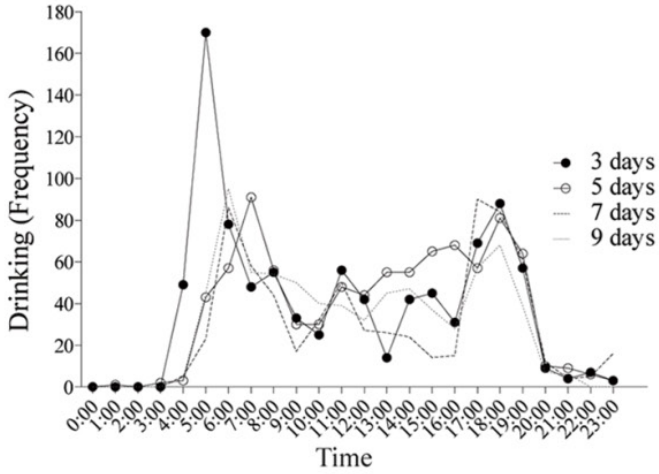

D

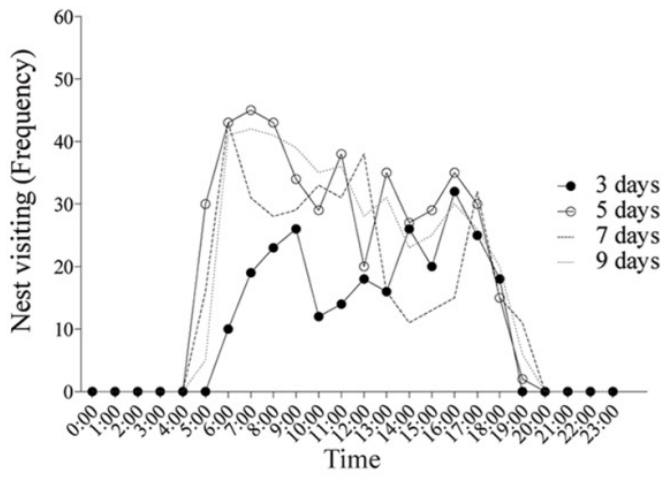

F

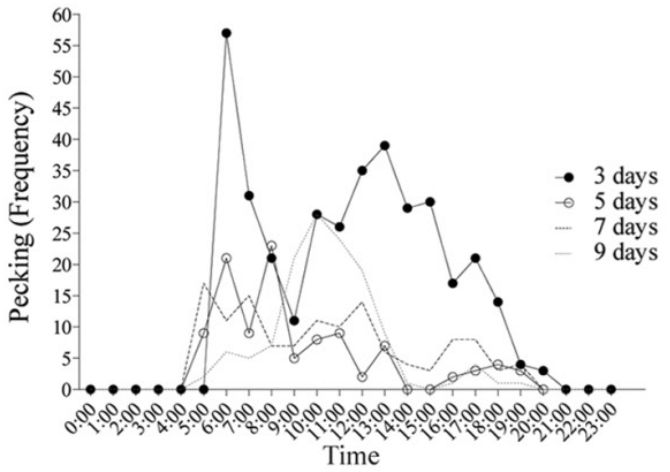

Fig. 4. Timing of behavioral changes in laying hens during the observation period. (A) Feeding, (B) Drinking, (C) Perching, (D) Nest visiting, (E) Dustbathing, (F) Pecking, (G) Wing flapping.

282

https://www.ejast.org

https://doi.org/10.5187/jast.2020.62.2.276 
A

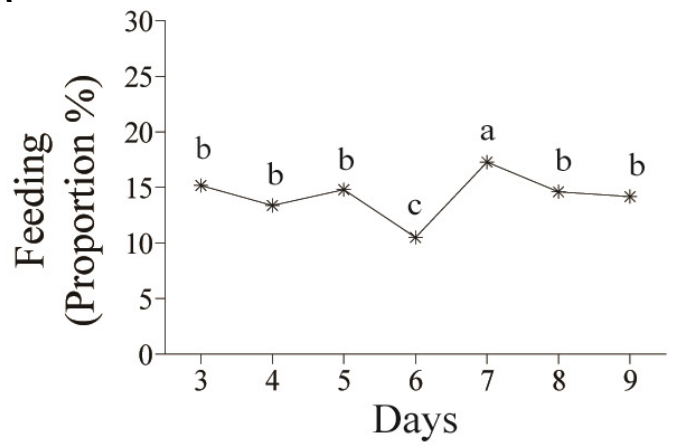

C

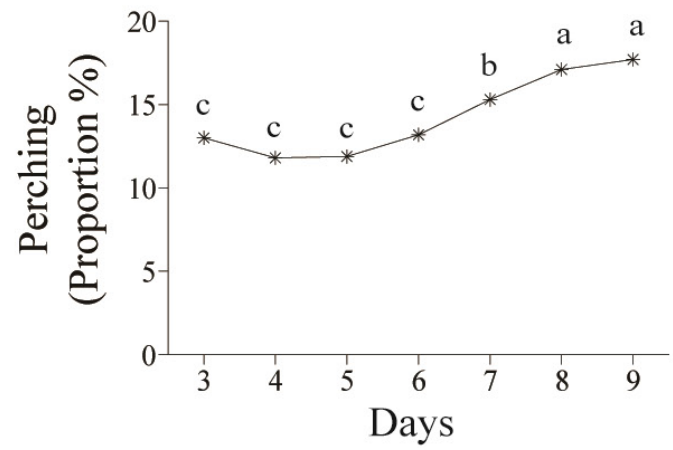

E

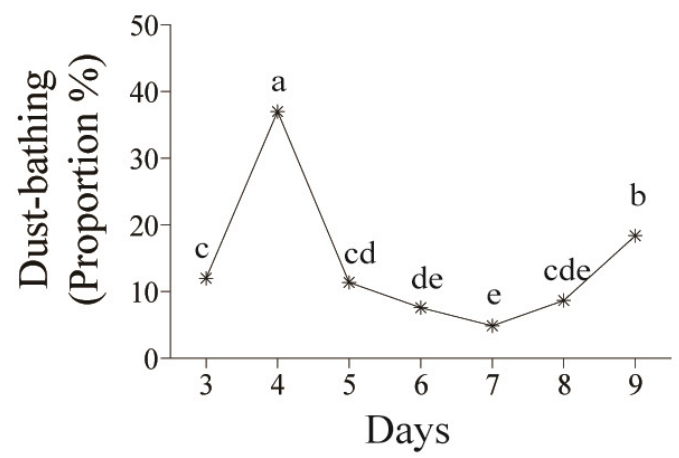

G

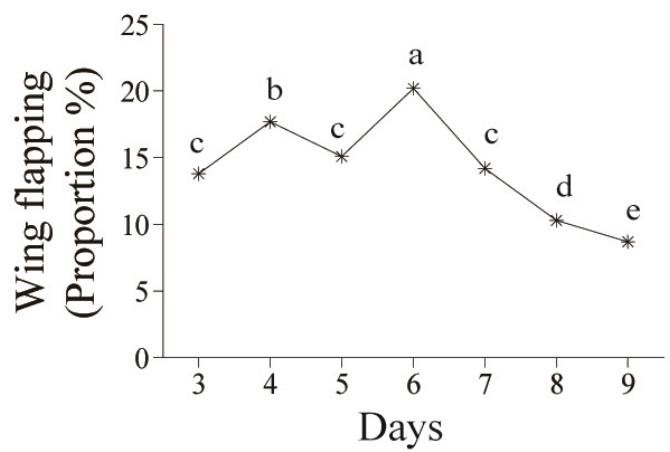

B

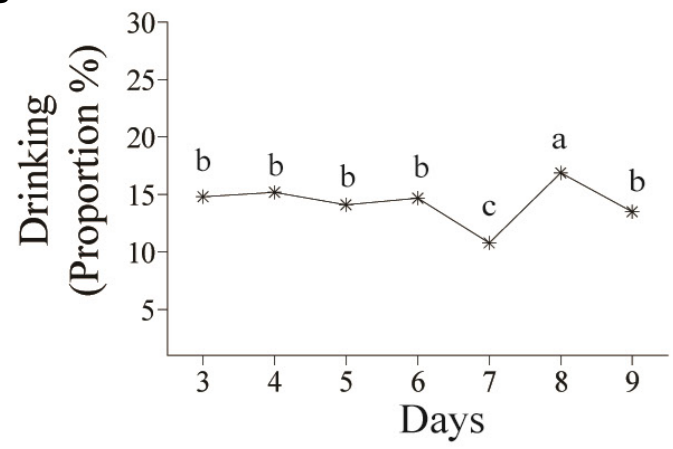

D

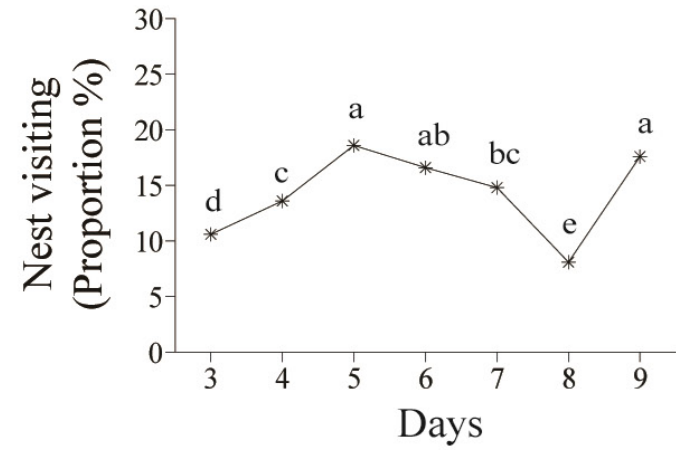

$\mathbf{F}$

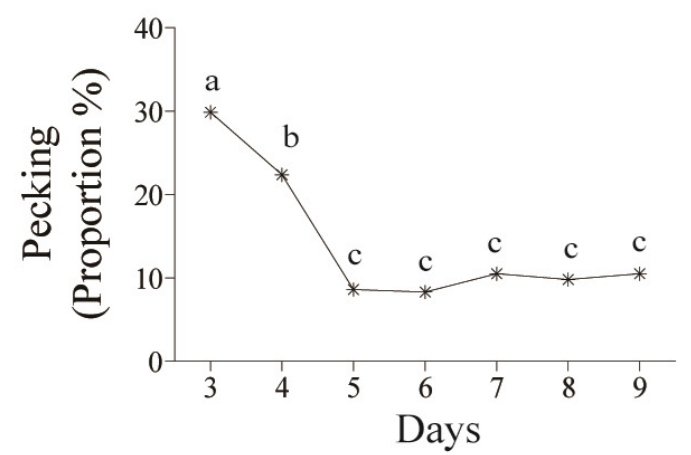

Fig. 5. Daily behavioral changes in the laying hens during the observation period. (A) Feeding, (B) Drinking, (C) Perching, (D) Nest visiting, (E) Dustbathing, (F) Pecking, (G) Wing flapping. ${ }^{\text {a-e }}$ Means within each parameter with different superscript letters are significantly different $(p<0.05)$. 
proposed that birds in large groups use other signals (body and comb size) to establish dominance relationships without fighting.

\section{Wing flapping}

Wing flapping is also important to evaluate for poultry welfare [59-62]. Several studies have shown that a lack of space restricts wing stretching/flapping and causes poor humerus health [63-65]. Wing flapping patterns largely coincided with feeding frequency for the first several days (Fig. 4g), but the patterns became less distinctive over days, suggesting a possible adaption of hens to the environment.

Wood-Gush [58] reported that wing flapping is higher in males than females as a displacement behavior during courtship or aggressive encounter. According to Nicol [61], a significant negative correlation is observed between dominance and wing flapping. Subordinate hens may have difficulty accessing the feeder and show increased wing flapping as a response to frustration or conflict. However, one study showed that dominant hens wing flap significantly more than subordinates because they are able to learn more quickly [66].

\section{Production}

Table 2 shows the production performance in three phases. Feed intake and egg production were consistently higher in the multi-tier system, whereas cracked and dirty eggs were more frequent in the floor system (Table 2; $p<0.001$ ). As the hens aged, feed intake and the eggs production

Table 2. Comparison of production performance between floor system and multi-tier system

\begin{tabular}{|c|c|c|}
\hline \multirow{2}{*}{ Variable } & \multicolumn{2}{|c|}{ Housing system } \\
\hline & Floor & Multi-tier \\
\hline \multicolumn{3}{|l|}{ Feed intake (g) } \\
\hline $17-23$ wk & $106.93 \pm 14.64^{B}$ & $125.37 \pm 21.96^{A}$ \\
\hline $24-30 w k$ & $100.54 \pm 26.54^{B}$ & $123.22 \pm 17.16^{A}$ \\
\hline $31-44$ wk & $103.09 \pm 20.17^{B}$ & $131.74 \pm 28.49^{A}$ \\
\hline \multicolumn{3}{|l|}{ Egg production (\%) } \\
\hline $17-23$ wk & $65.99 \pm 8.38^{\mathrm{Bb}}$ & $71.43 \pm 9.14^{\mathrm{Ab}}$ \\
\hline $24-30 w k$ & $70.05 \pm 1.82^{\mathrm{Ba}}$ & $80.15 \pm 5.68^{\mathrm{Aa}}$ \\
\hline $31-44$ wk & $70.89 \pm 2.47^{\mathrm{Ba}}$ & $79.49 \pm 4.49^{\mathrm{Aa}}$ \\
\hline \multicolumn{3}{|l|}{ Cracked eggs (\%) } \\
\hline $17-23$ wk & $3.48 \pm 0.73^{\mathrm{Aa}}$ & $1.38 \pm 0.66^{\mathrm{Ba}}$ \\
\hline $24-30 w k$ & $1.83 \pm 0.47^{\mathrm{Ab}}$ & $1.27 \pm 0.34^{\mathrm{Bab}}$ \\
\hline $31-44$ wk & $1.54 \pm 0.29^{A c}$ & $1.14 \pm 0.37^{\mathrm{Bb}}$ \\
\hline \multicolumn{3}{|l|}{ Dirty eggs (\%) } \\
\hline $17-23$ wk & $4.08 \pm 0.50^{\mathrm{Aa}}$ & $2.85 \pm 1.03^{\mathrm{Ba}}$ \\
\hline $24-30 w k$ & $2.37 \pm 0.40^{\mathrm{b}}$ & $2.12 \pm 0.79^{b}$ \\
\hline $31-44$ wk & $1.64 \pm 0.32^{\mathrm{Ac}}$ & $1.26 \pm 0.72^{\mathrm{BC}}$ \\
\hline \multicolumn{3}{|l|}{ Mortality (\%) } \\
\hline $17-23 w k$ & $0.00 \pm 0.00$ & $0.00 \pm 0.00$ \\
\hline $24-30 w k$ & $0.02 \pm 0.06$ & $0.01 \pm 0.05$ \\
\hline $31-44$ wk & $0.01 \pm 0.03$ & $0.01 \pm 0.05$ \\
\hline
\end{tabular}

Mean \pm standard deviation of several variables.

$\mathrm{A}, \mathrm{B}$ Means in rows with different superscripts differ significantly.

${ }^{\mathrm{a}-c}$ Means in columns with different superscripts differ significantly $(p<0.05)$. 
increased, whereas the numbers of cracked and dirty eggs decreased. Laying hens in the multi-tier system seemed to need more energy due to increased physical activity, because of the complexity of the housing system $[67,68]$. The separate spaces helped the layers exhibit specific behaviors while decreasing disturbance to others and promoting egg laying.

The reason for lower production in the floor system might be insufficient nest space. Crowded nest boxes caused a competition, especially for the more attractive nests [69]. Thus subordinate hens tended to delay laying eggs or laid eggs outside the nests, where stepping or pecking hens broke the eggs. An appropriate design of the nest box is very important in reducing cracked/dirty eggs and encouraging hens to use of the nest box [70,71]. The eggs rolled down a slope immediately after laying and were stored under the nests to prevent clutter in the nests. This helps prevent the laying hens from entering the nests at night and protect the eggs from accidents, egg pecking or breakage.

\section{Egg quality}

Table 3 shows the egg characteristics in three phases. The housing system did not affect egg quality, except albumen height at 23 weeks of age $(p<0.05)$, which was higher in eggs from hens in the floor system than the multi-tier system. Egg weight, eggshell weight, and albumen height increased significantly at 44 weeks of age in the floor system. Other parameters used to assess egg quality (eggshell thickness, eggshell strength, and $\mathrm{HU}$ increased significantly in the multi-tier system. Overall, egg quality improved with age between 23 and 44 weeks of age, so it was influenced by age rather than the housing system [72-74]. The mean weight of eggs at 44 weeks of age was > $64 \mathrm{~g}$ in both rearing systems being similar to others [75]. Many studies have compared production performance and egg quality between conventional cage and other housing systems. Studies showed no difference in these parameters between cage and aviary systems [76,77], higher egg weights in aviary vs. cage systems [78], and greater egg weights in the free-range system [74,79].

Eggshell color is important for consumer appeal. Korean consumers prefer brown eggs to white eggs [80]. No overall differences were found in eggshell colors, but the color decreased significantly with age of hens in the multi-tier system. It is shown that stressed laying hens retain their eggs in the shell gland beyond the normal oviposition time which causes brown eggs to appear paler [81,82]. In summer, eggshell color is lighter due to heat stress [83]. In addition, eggs laid in the morning are paler [84]. Walker [85] demonstrated that nest box design can influence eggshell color.

In the present experiment, eggshell quality, including eggshell weight, eggshell thickness, and eggshell strength increased with hen age regardless of the housing system. Eggshell weight increased by $2 \mathrm{~g}$ from 23 to 44 weeks of age in both housing systems. Eggshell thickness increased significantly in the multi-tier system. Yannakopoulos and Tserveni-Gousi [86] reported that the egg shell thickens with hen age, which is in agreement with our results. On the other hand, Silversides and Scott [87] reported a negative effect of age on eggshell thickness. Other studies have reported no significant effect $[74,88]$. Eggshell strength was higher in the floor system, than in the multi-tier system that possibly because of the different activity levels of the hens.

Yolk color also increased with age $(p<0.05)$. The average yolk color was 10.8 at 44 weeks in both housing systems. A preferred yolk color is 11 on the Roche scale in Australia Roberts [89]. The main contributing factors to yolk color are diet [90] and age and age [91,92]. Yolk color is greater in alternative systems compared to that in cage system $[91,93]$ and, in particular, free range hens have a darker yolk color because of xanthophyll intake from plants [74].

Our study demonstrated that albumen height did not differ between the housing systems, but influenced more with age. However, we did not find the exact cause as to why albumen height suddenly dropped at 30 weeks in hens from the floor system. All management was the same, and the data analysis was conducted by the same person. In some studies, ammonia within the housing 
Table 3. Comparison of egg quality in floor system and multi-tier system

\begin{tabular}{|c|c|c|}
\hline \multirow{2}{*}{ Variable } & \multicolumn{2}{|c|}{ Housing system } \\
\hline & Floor & Multi-tier \\
\hline \multicolumn{3}{|l|}{ Egg weight (g) } \\
\hline $23 w k$ & $53.98 \pm 5.60^{b}$ & $54.70 \pm 3.87^{c}$ \\
\hline $30 \mathrm{wk}$ & $54.93 \pm 6.00^{b}$ & $58.11 \pm 4.08^{b}$ \\
\hline 44 wk & $64.99 \pm 4.11^{\mathrm{a}}$ & $64.33 \pm 4.59^{\mathrm{a}}$ \\
\hline \multicolumn{3}{|l|}{ Eggshell color } \\
\hline $23 w k$ & $29.18 \pm 5.09$ & $31.20 \pm 2.98^{\mathrm{a}}$ \\
\hline $30 \mathrm{wk}$ & $27.99 \pm 3.95$ & $28.92 \pm 4.98^{\mathrm{a}}$ \\
\hline $44 w k$ & $27.48 \pm 3.67$ & $25.48 \pm 3.67^{b}$ \\
\hline \multicolumn{3}{|l|}{ Eggshell thickness (mm) } \\
\hline $23 w k$ & $0.34 \pm 0.03$ & $0.33 \pm 0.03^{b}$ \\
\hline $30 w k$ & $0.35 \pm 0.02$ & $0.34 \pm 0.02^{b}$ \\
\hline $44 \mathrm{wk}$ & $0.37 \pm 0.03$ & $0.38 \pm 0.03^{\mathrm{a}}$ \\
\hline \multicolumn{3}{|l|}{ Eggshell weight (g) } \\
\hline $23 w k$ & $6.94 \pm 0.94^{b}$ & $6.70 \pm 0.83^{c}$ \\
\hline $30 \mathrm{wk}$ & $7.24 \pm 0.66^{b}$ & $7.56 \pm 0.63^{b}$ \\
\hline $44 \mathrm{wk}$ & $9.15 \pm 0.49^{\mathrm{a}}$ & $8.87 \pm 0.90^{\mathrm{a}}$ \\
\hline \multicolumn{3}{|c|}{ Eggshell strength $\left(\mathrm{kg} / \mathrm{cm}^{2}\right)$} \\
\hline $23 w k$ & $4.01 \pm 0.89^{b}$ & $3.51 \pm 0.88^{c}$ \\
\hline $30 \mathrm{wk}$ & $4.82 \pm 1.06^{\mathrm{a}}$ & $4.24 \pm 0.99^{b}$ \\
\hline $44 \mathrm{wk}$ & $5.17 \pm 0.78^{\mathrm{a}}$ & $5.03 \pm 0.91^{\mathrm{a}}$ \\
\hline \multicolumn{3}{|l|}{ Yolk color } \\
\hline $23 w k$ & $7.26 \pm 1.21^{\mathrm{c}}$ & $7.60 \pm 0.86^{b}$ \\
\hline $30 \mathrm{wk}$ & $8.17 \pm 0.90^{b}$ & $7.79 \pm 0.89^{b}$ \\
\hline 44 wk & $10.75 \pm 0.43^{\mathrm{a}}$ & $10.75 \pm 0.62^{\mathrm{a}}$ \\
\hline \multicolumn{3}{|l|}{ Albumen height (mm) } \\
\hline $23 w k$ & $7.48 \pm 1.66^{\mathrm{ab}}$ & $7.43 \pm 1.28^{b}$ \\
\hline $30 \mathrm{wk}$ & $6.81 \pm 1.55^{\mathrm{Bb}}$ & $7.87 \pm 1.37^{A b}$ \\
\hline $44 \mathrm{wk}$ & $8.08 \pm 0.87^{\mathrm{a}}$ & $8.24 \pm 1.06^{a}$ \\
\hline \multicolumn{3}{|l|}{ Haugh unit } \\
\hline $23 w k$ & $87.40 \pm 9.80$ & $87.21 \pm 7.96^{b}$ \\
\hline $30 \mathrm{wk}$ & $83.19 \pm 11.03$ & $88.71 \pm 8.71^{b}$ \\
\hline $44 w k$ & $88.75 \pm 5.03$ & $89.52 \pm 5.70^{\mathrm{a}}$ \\
\hline
\end{tabular}

Mean \pm standard deviation of several variables.

${ }^{A, B}$ Means in rows with different superscripts differ significantly.

${ }^{a-c}$ Means in columns with different superscripts differ significantly $(p<0.05)$.

system affected albumen height [92,94] and Koerkamp et al. [95] reported that ammonia is higher in the floor system compared to a multi-tier system.

$\mathrm{HU}$ is an objective measure of egg quality that is influenced by age, diet, bacterial infection, ammonia, storage time, and storage temperature [89]. In our study, no differences were detected in $\mathrm{HU}$ between the two housing systems, although $\mathrm{HU}$ decreased at 30 weeks in hens with a reduced albumen height. $\mathrm{HU}$ in the multi-tier system increased with hen age $(p<0.05)$. 


\section{CONCLUSION}

We observed that laying hens might need at least seven days to adapt to the multi-tier system. We also didn't find any problems in access to perches and nests. Moreover, the egg production was higher in multi-tier system than in the floor system, whereas the cracked and dirty eggs were lower in multi-tier system than in the floor system. These results suggest that the multi-tier system evaluated here is expected to be suitable as an alternative housing system to the floor system for laying hen in Korea, as the system increased productivity and improved welfare of the hens. There are still potential conflicts between animal welfare and farm economics. However, further study on the welfare assessment of laying hens in this multi-tier would be useful.

\section{REFERENCES}

1. Newberry RC. Environmental enrichment: increasing the biological relevance of captive environments. Appl Anim Behav Sci. 1995;44:229-43.

2. Campbell DLM, Makagon MM, Swanson JC, Siegford JM. Perch use by laying hens in a commercial aviary. Poult Sci. 2016;95:1736-42.

3. Tauson R. Management and housing systems for layers: effects on welfare and production. Worlds Poult Sci J. 2005;61:477-90.

4. Janczak AM, Riber AB. Review of rearing-related factors affecting the welfare of laying hens. Poult Sci. 2015;94:1454-69.

5. de Haas EN, Bolhuis JE, de Jong IC, Kemp B, Janczak AM, Rodenburg TB. Predicting feather damage in laying hens during the laying period. Is it the past or is it the present? Appl Anim Behav Sci. 2014;160:75-85.

6. Campbell DLM, de Haas EN, Lee C. A review of environmental enrichment for laying hens during rearing in relation to their behavioral and physiological development. Poult Sci. 2019;98:9-28.

7. Channing CE, Hughes BO, Walker AW. Spatial distribution and behaviour of laying hens housed in an alternative system. Appl Anim Behav Sci. 2001;72:335-45.

8. Choi JH, Namkung H, Paik IK. Feed consumption pattern of laying hens in relation to time of oviposition. Asian-Australas J Anim Sci. 2004;17:371-3.

9. Jordan D, Faruk MU, Lescoat P, Ali MN, Štuhec I, Bessei W, et al. The influence of sequential feeding on behaviour, feed intake and feather condition in laying hens. Appl Anim Behav Sci. 2010;127:115-24.

10. Hetland H, Svihus B, Lervik S, Moe R. Effect of feed structure on performance and welfare in laying hens housed in conventional and furnished cages. Acta Agric Scand A Anim Sci. 2003;53:92-100.

11. Savory CJ. Diurnal feeding patterns in domestic fowls: a review. Appl Anim Ethol. 1980;6:7182.

12. Savory CJ. Effects of egg production on the pattern of food intake of broiler hens kept in continuous light. Br Poult Sci. 1977;18:331-7.

13. Wood-Gush DGM, Horne AR. The effect of egg formation and laying on the food and water intake of Brown Leghorn hens. Br Poult Sci. 1970;11:459-66.

14. Cunningham DL, Van Tienhoven A. Relationship between production factors and dominance in White Leghorn hens in a study on social rank and cage design. Appl Anim Ethol. 1983;11:33-44.

15. Meunier-Salaün MC, Faure JM. On the feeding and social behaviour of the laying hen. Appl 
Anim Behav Sci. 1984;13:129-41.

16. Huon F, Meunier-Salaün MC, Faure JM. Feeder design and available feeding space influence the feeding behaviour of hens. Appl Anim Behav Sci.1986;15:65-70.

17. Albentosa MJ, Cooper JJ, Luddem T, Redgate SE, Elson HA, Walker AW. Evaluation of the effects of cage height and stocking density on the behaviour of laying hens in furnished cages. Br Poult Sci. 2007;48:1-11.

18. Appleby MC. Perch length in cages for medium hybrid laying hens. Br Poult Sci. 1995;36:2331.

19. Tauson R. Effects of a perch in conventional cages for laying hens. Acta Agri Scand. 1984;34:193-209.

20. Olsson IAS, Keeling LJ. The push-door for measuring motivation in hens: laying hens are motivated to perch at night. Anim Welf. 2002;11:11-9.

21. Blokhuis HJ. Rest in poultry. Appl Anim Behav Sci. 1984;12:289-303.

22. Olsson IAS, Keeling LJ. Night-time roosting in laying hens and the effect of thwarting access to perches. Appl Anim Behav Sci. 2000;68:243-56.

23. Brake J, Keeley TP, Jones RB. Effect of age and presence of perches during rearing on tonic immobility fear reactions of broiler breeder pullets. Poult Sci. 1994;73:1470-4.

24. Brendler C, Kipper S, Schrader L. Vigilance and roosting behaviour of laying hens on different perch heights. Appl Anim Behav Sci. 2014;157:93-9.

25. Cordiner LS, Savory CJ. Use of perches and nestboxes by laying hens in relation to social status, based on examination of consistency of ranking orders and frequency of interaction. Appl Anim Behav Sci. 2001;71:305-17.

26. Gunnarsson S, Yngvesson J, Keeling LJ, Forkman B. Rearing without early access to perches impairs the spatial skills of laying hens. Appl Anim Behav Sci. 2000;67:217-28.

27. Wichman A, Heikkilä M, Valros A, Forkman B, Keeling LJ. Perching behaviour in chickens and its relation to spatial ability. Appl Anim Behav Sci. 2007;105:165-79.

28. Fleming RH, Whitehead CC, Alvey D, Gregory NG, Wilkins LJ. Bone structure and breaking strength in laying hens housed in different husbandry systems. Br Poult Sci. 1994;35:651-62.

29. Nørgaard-Nielsen G. Bone strength of laying hens kept in an alternative system, compared with hens in cages and on deep-litter. Br Poult Sci. 1990;31:81-9.

30. Duncan IJH, Savory CJ, Wood-Gush DGM. Observations on the reproductive behaviour of domestic fowl in the wild. Appl Anim Ethol. 1978;4:29-42.

31. Kruschwitz A, Zupan M, Buchwalder T, Huber-Eicher B. Nest preference of laying hens (Gallus gallus domesticus) and their motivation to exert themselves to gain nest access. Appl Anim Behav Sci. 2008;112:321-30.

32. Lundberg A, Keeling LJ. The impact of social factors on nesting in laying hens (Gallus gallus domesticus). Appl Anim Behav Sci.1999;64:57-69.

33. Riber AB. Development with age of nest box use and gregarious nesting in laying hens. Appl Anim Behav Sci. 2010;123:24-31.

34. Appleby MC, McRae HE. The individual nest box as a super-stimulus for domestic hens. Appl Anim Behav Sci. 1986;15:169-76.

35. Appleby MC, Smith SF. Design of nest boxes for laying cages. Br Poult Sci. 1991;32:667-78.

36. Buchwalder T, Fröhlich EK. Assessment of colony nests for laying hens in conjunction with the authorization procedure. Appl Anim Behav Sci. 2011;134:64-71.

37. Struelens E, Van Nuffel A, Tuyttens FAM, Audoorn L, Vranken E, Zoons J, et al. Influence of nest seclusion and nesting material on pre-laying behaviour of laying hens. Appl Anim Behav Sci. 2008;112:106-19. 
38. Zupan M, Kruschwitz A, Huber-Eicher B. The influence of light intensity during early exposure to colours on the choice of nest colours by laying hens. Appl Anim Behav Sci. 2007;105:154-64.

39. Rietveld-Piepers B, Blokhuis HJ, Wiepkema PR. Egg-laying behaviour and nest-site selection of domestic hens kept in small floor-pens. Appl Anim Behav Sci. 1985;14:75-88.

40. Freire R, Appleby MC, Hughes BO. Effects of social interactions on pre-laying behaviour in hens. Appl Anim Behav Sci. 1998;56:47-57.

41. Lentfer TL, Gebhardt-Henrich SG, Fröhlich EK, von Borell E. Nest use is influenced by the positions of nests and drinkers in aviaries. Poult Sci. 2013;92:1433-42.

42. Sherwin CM, Nicol CJ. Factors influencing floor-laying by hens in modified cages. Appl Anim Behav Sci. 1993;36:211-22.

43. van Liere DW, Kooijman J, Wiepkema PR. Dustbathing behaviour of laying hens as related to quality of dustbathing material. Appl Anim Behav Sci. 1990;26:127-41.

44. Vestergaard K. Dust-bathing in the domestic fowl: diurnal rhythm and dust deprivation. Appl Anim Ethol. 1982;8:487-95.

45. Duncan IJH, Widowski TM, Malleau AE, Lindberg AC, Petherick JC. External factors and causation of dustbathing in domestic hens. Behav Proc. 1998;43:219-28.

46. Hogan JA, van Boxel F. Causal factors controlling dustbathing in Burmese red junglefowl: some results and a model. Anim Behav. 1993;46:627-35.

47. Nicol CJ, Lindberg AC, Phillips AJ, Pope SJ, Wilkins LJ, Green LE. Influence of prior exposure to wood shavings on feather pecking, dustbathing and foraging in adult laying hens. Appl Anim Behav Sci. 2001;73:141-55.

48. Sanotra GS, Vestergaard KS, Agger JF, Lawson LG. The relative preferences for feathers, straw, wood-shavings and sand for dustbathing, pecking and scratching in domestic chicks. Appl Anim Behav Sci. 1995;43:263-77.

49. Wichman A, Keeling LJ. Hens are motivated to dustbathe in peat irrespective of being reared with or without a suitable dustbathing substrate. Anim Behav. 2008;75:1525-33.

50. Orság J, Brouček J, Mačuhová L, Knížatová M, Flak P, Hanus A. Behaviour of hens deprived of dustbathing. Slovak J Anim Sci. 2011;44:65-71.

51. Gentle MJ, Hunter LN. Physiological and behavioural responses associated with feather removal in Gallus gallus var domesticus. Res Vet Sci. 1991;50:95-101.

52. Savory CJ. Feather pecking and cannibalism. Worlds Poult Sci J.1995;51:215-9.

53. Blokhuis HJ, van Niekerk TF, Bessei W, Elson A, Guémené D, Kjaer JB, et al. The LayWel project: welfare implications of changes in production systems for laying hens. Worlds Poult Sci J. 2007;63:101-14.

54. Ramadan SGA, Von Borell E. Role of loose feathers on the development of feather pecking in laying hens. Br Poult Sci. 2008;49:250-6.

55. Nicol CJ, Gregory NG, Knowles TG, Parkman ID, Wilkins LJ. Differential effects of increased stocking density, mediated by increased flock size, on feather pecking and aggression in laying hens. Appl Anim Behav Sci. 1999;65:137-52.

56. Wechsler B, Huber-Eicher B. The effect of foraging material and perch height on feather pecking and feather damage in laying hens. Appl Anim Behav Sci. 1998:58:131-41.

57. Blokhuis HJ, Wiepkema PR. Studies of feather pecking in poultry. Vet Quart. 1998;20:6-9.

58. Wood-Gush DGM. The behaviour of the domestic fowl. London: Heinemann Educational Books Ltd; 1971.

59. Albentosa MJ, Cooper JJ. Effects of cage height and stocking density on the frequency of comfort behaviours performed by laying hens housed in furnished cages. Anim Welf. 2004;13:419- 
24.

60. Carmichael NL, Walker W, Hughes BO. Laying hens in large flocks in a perchery system: influence of stocking density on location, use of resources and behaviour. Br Poult Sci. 1999;40:165-76.

61. Nicol CJ. Social influences on the comfort behaviour of laying hens. Appl Anim Behav Sci. 1989;22:75-81.

62. Shimmura T, Eguchi Y, Uetake K, Tanaka T. Behavior, performance and physical condition of laying hens in conventional and small furnished cages. Anim Sci J. 2007;78:323-9.

63. Dawkins MS, Hardie S. Space needs of laying hens. Br Poult Sci. 1989;30:413-6.

64. Nicol CJ. Behavioural responses of laying hens following a period of spatial restriction. Anim Behav. 1987;35:1709-19.

65. Tanaka T, Hurnik JF. The behavior of young layers during the first two weeks in aviary and battery cages. Poult Sci. 1991;70:404-7.

66. Croney CC, Prince-Kelly N, Meller CL. A note on social dominance and learning ability in the domestic chicken (Gallus gallus). Appl Anim Behav Sci. 2007;105:254-8.

67. Preisinger R. Lohmann tradition, praxiserfahrung und entwicklungsperspektiven. Lohmann Inform. 2000; 3:13-6.

68. Sosnówka-Czajka E, Herbut E, Skomorucha I. Effect of different housing systems on productivity and welfare of laying hens. Ann Anim Sci. 2010;10:349-60.

69. Hunniford ME, Torrey S, Bédécarrats G, Duncan IJH, Widowski TM. Evidence of competition for nest sites by laying hens in large furnished cages. Appl Anim Behav Sci. 2014; 161:95104.

70. Abrahamsson P, Tauson R. Performance and egg quality of laying hens in an aviary system. J Appl Poult Res. 1998;7:225-32 .

71. Guesdon V, Faure JM. Laying performance and egg quality in hens kept in standard or furnished cages. Anim Res. 2004;53:45-57.

72. Johnston SA, Gous RM. Modelling the changes in the proportions of the egg components during a laying cycle. Br Poult Sci. 2007;48:347-53.

73. Silversides FG, Scott TA. Effect of storage and layer age on quality of eggs from two lines of hens. Poult Sci. 2001;80:1240-5.

74. Van Den Brand H, Parmentier HK, Kemp B. Effects of housing system (outdoor vs cages) and age of laying hens on egg characteristics. Br Poult Sci. 2004;45:745-52.

75. Hy-Line International. Hy-Line brown commercial layers: management guide. West Des Moines, IA: Hy-Line International; 2014.

76. Basmacioglu H, Ergul M. Research on the factors affecting cholesterol content and some other characteristics of eggs in laying hens the effects of genotype and rearing system. Turk J Vet Anim Sci. 2005;29:157-64.

77. Aerni V, Brinkhof MWG, Wechsler B, Oester H, Fröhlich E. Productivity and mortality of laying hens in aviaries: a systematic review. Worlds Poult Sci J. 2005;61:130-42.

78. Abrahamsson P, Tauson R, Elwinger K. Effects on production, health and egg quality of varying proportions of wheat and barley in diets for two hybrids of laying hens kept in different housing systems. Acta Agric Scand A Anim Sci. 1996;46:173-82.

79. Mostert BE, Bowes EH, van der Walt JC. Influence of different housing systems on the performance of hens of four laying strains. S Afr J Anim Sci. 1995;25:80-6.

80. Lee DH, Han SW, Lee BD, Ohh BK, Kim KS. Consumer preference for eggshell color in Korea - eggs from the research of developing fowl typhoid resistant strains. Korean J Poult Sci. 2003;30:29-34. 
81. Hughes BO, Gilbert AB, Brown MF. Categorisation and causes of abnormal egg shells: relationship with stress. Br Poult Sci. 1986;27:325-37.

82. Reynard M, Savory CJ. Stress-induced oviposition delays in laying hens: duration and consequences for eggshell quality. Brit Poult Sci. 1999;40:585-91.

83. Odabaşi AZ, Miles RD, Balaban MO, Portier KM. Changes in brown eggshell color as the hen ages. Poult Sci. 2007;86:356-63.

84. Campo JL, Gil MG, Dávila SG. Differences among white-, tinted-, and brown-egg laying hens for in-cidence of eggs laid on the floor and for oviposition time. Arch Geflügelk. 2007;71:1059.

85. Walker AW. Egg shell colour is affected by laying cage design. Br Poult Sci. 1998;39:696-9.

86. Yannakopoulos AL, Tserveni-Gousi AS. Relationship of parents' age, hatching egg weight, and shell quality to day-old chick weight as influenced by oviposition time. Poult Sci. 1987;66:82933.

87. Silversides FG, Scott TA. Effect of storage and layer age on quality of eggs from two lines of hens. Poult Sci. 2001;80:1240-5.

88. Yannakopoulos AL, Tserveni-Gousi AS, Nikokyris P. Egg composition as influenced by time of oviposition, egg weight, and age of hens. Arch Geflügelk.1994;58:206-13.

89. Roberts JR. Factors affecting egg internal quality and egg shell quality in laying hens. J Poult Sci. 2004;41:161-77.

90. Lesson S, Summers JD. Commercial poultry nutrition. Guelph: University Books; 1991. p. 77148.

91. Pištěková V, Hovorka M, Večerek V, Straková E, Suchý P. The quality comparison of eggs laid by laying hens kept in battery cages and in a deep litter system. Czech J Anim Sci. 2006;51:318-25.

92. Singh R, Cheng KM, Silversides FG. Production performance and egg quality of four strains of laying hens kept in conventional cages and floor pens. Poult Sci. 2009;88:256-64.

93. Senčić $Đ$, Butko D. Productivity of layers and egg quality in free range and cage system of housing. Poljoprivreda. 2006;12:48-51.

94. Ahammed M, Chae BJ, Lohakare J, Keohavong B, Lee MH, Lee SJ, et al. Comparison of aviary, barn and conventional cage raising of chickens on laying performance and egg quality. Asian-Australas J Anim Sci. 2014;27:1196-203.

95. Groot Koerkamp PWG, Speelman L, Metz, JHM. Litter composition and ammonia emission in aviary houses for laying hens. Part 1: performance of a litter drying system.J Agric Eng Res. 1998;70:375-82. 